\title{
Using m-commerce to achieve strategic objectives in South African retail organisations
}

\author{
Jeremy Sissing ${ }^{1}$, Nomusa Nomhle Dlamini ${ }^{2 *}$, Kevin Johnston ${ }^{3}$ \\ 1, 2, 3 Department of Information Systems, University of Cape Town, Cape Town, South Africa
}

\author{
Index Terms \\ Component \\ Formatting \\ M-commerce \\ IT Strategy \\ South African Retail Market
}

Received: 4 September 2016 Accepted: 10 October 2016

Published: 12 February 2017

\begin{abstract}
The paper aims to explore how South African retail organisations can use m-commerce to achieve their strategic objectives. Strategic objectives include increased return on capital, improved operating quality and efficiency, growing high-value customer relationships, accelerating product innovation, and creating a high-performance culture. Research questions were generated from a strategy map that identified five strategic themes, each with its own objectives. A qualitative approach to the research was taken with open-ended interview questions, and thematic analysis was used to analyse the data. The literature and the data analysis findings indicated that South African retail organisations could use m-commerce to achieve all the strategic objectives. However, the findings indicate that m-commerce, within the South African retail context, is more suited to increasing return on capital, growing high-value customer relationships, and improving operating quality and efficiency. The literature surveyed highlighted that there could be an opportunity for retail organisations within South Africa to achieve their strategic objectives by implementing effective m-commerce strategies which are aligned with the business strategy. Therefore, improving and updating their business processes and modifying their business models to maximize the potential opportunity to create a competitive advantage.
\end{abstract}

(C) 2017 The Author(s). Published by TAF Publishing.

\section{INTRODUCTION}

"The emergence of mobile commerce (m-commerce) has gained the attention of both practitioners and researchers due to its potential impact on business and industry" [1]. M-commerce makes electronic commerce (ecommerce) activities more convenient as users or customers do not require conventional computers to conduct business or, in the case of retail, make purchases via the internet [2], [3] and [4]. M-commerce allows the customer to browse catalogues and purchase goods online wherever they are, and whenever convenient [3]. "It is similar to ecommerce except that the transactions by m-commerce are through a mobile device via wireless connections" [2]. A competitive advantage could potentially be gained using $\mathrm{m}$ commerce, especially within the retail industry, by bringing the purchasing power to the customer and strengthening or building customer relationships [3], [5] and [24]. There could therefore be an opportunity for retail organisations within South Africa to achieve their strategic objectives by implementing effective $\mathrm{m}$-commerce strategies which are aligned with the business strategy, which can improve and update their business processes and can modify their business models in order to maximise the potential opportunity to create a competitive advantage [6], [7], [8]. This is, however an extremely difficult task as there are many different strategic business and technological considerations and decisions that have to be made [7], [25] and [8].

\footnotetext{
* Corresponding author: Nomusa Nomhle Dlamini

${ }^{\dagger}$ Email: DLMNOM036@myuct.ac.za
} 
The purpose of this paper is to present how South African retail organisations can use mobile commerce (mcommerce) to achieve their strategic objectives.

Strategy map and conceptual framework were used to determine how South African retail organisations can use $\mathrm{m}$-commerce to increase return on capital, improve operating quality and efficiency, grow high value customer relationships, accelerate product innovation and create a high performance culture [9]. Research questions were then formulated from the strategy map. The research is based on an interpretive philosophy and therefore an inductive, qualitative approach was taken.

The University of Cape Town (UCT) online library was used to search for literature. Within the library databases that were searched included: Google Scholar, EBSCO Host, ACM Portal, Web of Knowledge and Emerald database platforms [10].

\section{LITERATURE REVIEW}

The strategy map shown in Figure 1, by [9] was used to illustrate corporate strategy. The strategy map formed the basis of the conceptual framework used for research on the topic. This strategy map and conceptual framework was also used by [11] to determine if cloud computing can be used to achieve the strategic objectives of South African enterprises. The strategy map separates corporate strategy into five strategic themes which are: increase return on capital, improve operating quality and efficiency, grow high value customer relationships, accelerate product innovation and create a high performance culture [9]. Each of these strategic themes has its own objectives which can be seen labelled in Figure 1 (e.g. F1 Improve productivity). The research used the same labelling (e.g. F1, F2) as used by [11] for simplicity and readability purposes.

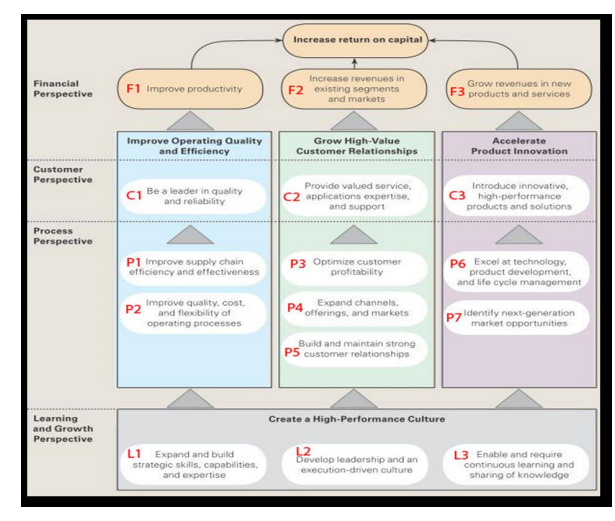

Fig. 1. Strategy map [9]

ISSN: 2414-3103

DOI: $10.20474 /$ japs-3.1.2

\section{A. Increase Return on Capital}

[9] suggest that an organisation can increase return on capital by improving productivity (F1), increasing revenues in existing segments and markets (F2), and by growing revenues in new products and services (F3).

F.1: Improve productivity:

Organisations can use m-commerce to improve productivity (F1) as it enables their employees to do their jobs more efficiently and creates a competitive advantage by enabling quality decision making using real time information at any time and place [12] and [13].

F.2: Increase revenues in existing segments and markets:

[13] stated that m-commerce can be used to increase revenues in existing segments and markets (F2) by making use of the convenience, mobility and marketing opportunities it provides.

F3: Grow revenues in new products and services:

M-commerce can be used to grow revenues in new products and services (F3) by bringing new services and products to the hand of the user and taking full advantage of mobile specific services like location-based services [13] and [14]. The literature indicates that strategic objectives (F1, F2 and F3) can be achieved by implementing $\mathrm{m}$-commerce, which leads to the research question 1.

Research question 1:

Can m-commerce be used by South African retail organisations to improve F1, F2, F3 objectives, thus increasing return on capital?

\section{B. Improve Operating Quality and Efficiency}

An organisation can improve operating quality and efficiency by being a leader in quality and reliability (C1), improving supply chain efficiency and effectiveness (P1), and by improving the quality, cost and flexibility of operating processes (P2) [9].

C1: Be a leader in quality and reliability:

M-commerce can be used to enable the organisation to be a leader in quality and reliability (C1) by giving employees access to the correct information at any place and any time, allowing them to work more effectively and efficiently resulting in a high quality, reliable operating environment [13] and [15].

P1: Improve supply chain efficiency and effectiveness:

[14] and [16] stated that m-commerce can be used by organisations to improve supply chain efficiency and effectiveness (P1) by taking advantage of the mobility, connectivity, productivity and communication of $\mathrm{m}$-commerce. 
P2: Improve the quality, cost and flexibility of operating processes:

M-commerce can be used to improve the quality, cost and flexibility of operating processes (P2) through the mobility, flexibility, collaboration and communication advantages it provides [13].

The literature indicates that being a leader in quality and reliability, improving supply chain efficiency and effectiveness and improving the quality, cost and flexibility of operating processes are strategic objectives that can be achieved by implementing $\mathrm{m}$-commerce. This leads to the research question 2 .

Research question 2:

Can m-commerce be used by South African retail organisations to achieve C1, P1, P2 objectives, thus improving operating quality and efficiency?

\section{Grow High-Value Customer Relationships}

[9] suggest that an organisation can grow high value customer relationships by providing valued service, applications expertise and support (C2), by optimising customer profitability (P3), by expanding channels, offerings and markets (P4), and by building and maintaining strong customer relationships (P5).

C2: Provide valued service, applications expertise, and support Organisations can use m-commerce to provide valued service, applications services and support (C2) by providing mobility, flexibility, convenience and improving communication between both the organisation and the customers.

\section{P3: Optimise customer profitability:}

[14] stated that organisations can use m-commerce to optimise customer profitability (P3) by providing the customer with flexibility and convenience and by taking advantage of location-aware services and target marketing. P4: Expand channels, offerings and markets:

Organisations can expand channels, offerings and markets (P4) by taking advantage of new marketing strategies which are made possible [16].

\section{P5: Build and maintain strong customer relationships:}

Organisations can build and maintain strong customer relationships (P5) by providing the customer with valuable and convenient $\mathrm{m}$-commerce services, providing better customer service and by improving marketing and communication with the customer [13] and [14]. The literature indicates that strategic objectives: providing valued service, applications expertise, and support; optimising customer profitability; expanding channels, offerings and markets; and building and maintaining strong customer relationships can be achieved by implementing m-commerce. This leads to the research question 3.

Research Question 3:

Can m-commerce be used by South African retail organisations to achieve C2, P3, P4 and P5 objectives, thus growing high-value customer relationships?

\section{Accelerate product Innovation}

An organisation can accelerate product innovation by introducing innovative, high-performance products and solutions (C3), by excelling in technology, product development and life cycle management (P6), and by identifying next generation market opportunities (P7) [9].

C3: Introduce innovative, high-performance products and solutions Organisations can use m-commerce to introduce innovative, high-performance products and solutions (C3) by taking advantage of m-commerce benefits when developing products and solutions, using services like location-aware services and also by providing employees with time to be innovative due to their increased productivity [13] and [14].

P6: Excel at technology, product development, and life cycle management:

[13] mentioned that organisations can use mcommerce to excel in technology, product development and life cycle management (P6) by improving employee productivity and efficiency in product development as well as improving the integration and communication of life cycle management.

P7: Identify next generation market opportunities:

Organisations can use m-commerce to identify next generation market opportunities (P7) by providing new opportunities for market growth and by being a link in the progression from e-commerce to u-commerce which can be seen as a new generation marketing opportunity [12].

The literature indicates that introducing innovative, high-performance products and solutions; excelling in technology, product development, and life cycle management; and identifying next generation market opportunities can be achieved by implementing m-commerce. This leads to the research question 4 .

Research question 4:

Can m-commerce be used by South African retail organisations to achieve C3, P6 and P7 objectives, thus accelerating product innovation? 


\section{E. Create a High Performance Culture}

[13] suggest that an organisation can create a high performance culture by expanding and building strategic skills, capabilities and expertise (L1), by developing a leadership and execution driven culture (L2), and by enabling continuous learning and sharing of knowledge (L3).

L1: Expand and build strategic skills, capabilities and expertise:

[13], [15] and [17] stated that organisations can use m-commerce to expand and build strategic skills, capabilities and expertise (L1) by employees making use of its mobility, accessibility, efficiency and communication abilities to facilitate learning, develop appropriate skills and create time to focus on improvement.

\section{L2: Develop a leadership and an execution -driven culture:}

Organisations can use m-commerce to develop a leadership and execution-driven culture (L2) by providing employees with real-time information which enables them to make informed decisions, executes transactions or tasks, and encourages leadership [13], [15] and [16].

L3: Enable continuous learning and sharing of knowledge:

Organisations can use m-commerce to enable continuous learning and sharing of knowledge (L3) by improving the availability of knowledge by taking advantage of its mobility and flexibility [13], [15] and [16].

Literature Review indicated that strategic objectives of expanding and building strategic skills, capabilities and expertise; developing a leadership and an execution -driven culture and enabling continuous learning and sharing of knowledge objectives can be achieved by implementing $\mathrm{m}$ commerce, which leads to research question 5 .

Research question 5 :

Can m-commerce be used by South African retail organisations to achieve L1, L2 and L3 objectives, thus creating a high performance culture?

\section{METHODOLOGY}

An interpretive philosophy to the research was used to determine if South African retail organisations can use m-commerce to achieve their strategic objectives. An interpretive philosophy has been used as it investigates questions that are unexplored and is based on "lived experiences of reality and not an objective, knowable reality beyond the human mind" [11]. Furthermore, a qualitative research approach was taken as it allows the researcher to understand the respondents' circumstances, options and decisions at a deeper level [18].

Qualitative research is also more inductive and subjective, which suits the interpretive approach of this research, as compared to the objective and deductive approach of the quantitative approach [11]. Semi-structured interviews were the qualitative method applied as they use open-ended questions which allow for conversational flow and provide a more in depth understanding of the research problem as perceived by the respondent [19].

\section{A. Data Collection}

The data were collected by conducting semistructured interviews with nine respondents from South African retail organisations based in Cape Town. The population of the research was IT managers or e-commerce managers of South African retail organisations that currently have a m-commerce strategy in place or are in the process of implementing one.

\section{FINDINGS}

Thematic analysis was used to analyse and report on the data generated from the interviews. Thematic analysis can produce rich information by thoroughly reading and rereading the data and identifying patterns and themes [11].

TABLE 1

RESPONDENTS' DEMOGRAPHICS

\begin{tabular}{llll}
\hline \hline Name & Position & Location & Medium \\
\hline Sean & E-commerce manager & Cape Town & Face to face \\
William & E-commerce manager & Cape Town & Face to face \\
Brian & E-commerce manager & Cape Town & Face to face \\
James & IT manager & Cape Town & Face to face \\
Mark & IT manager & Cape Town & Face to face \\
Tim & E-commerce manager & Cape Town & Telephone \\
Wayne & IT manager & Cape Town & Telephone \\
Billy & IT manager & Cape Town & Telephone \\
Sam & IT manager & Cape Town & Telephone \\
\hline \hline
\end{tabular}




\section{A. Sample Data}

Interviews were conducted with nine respondents from South African retail organisations based in Cape Town, of which four respondents were e-commerce managers and five respondents were IT managers. Pseudonyms were given to all the respondents for confidentiality purposes, their demographics are shown in table 1.

\section{B. Increase Return on Capital}

\section{F.1: Improve productivity:}

All nine respondents agreed with the literature which suggested that the mobility that $\mathrm{m}$-commerce allows enables employees to be more productive [16].

Six of these respondents mentioned that mcommerce allows employees to be more productive because they are easily accessible and have easy access to real time information while being mobile, which also supports the literature [14], [15] and [17]. The literature and seven respondents suggested that employees can work more efficiently using m-commerce which will improve productivity [13]. Brian said that by using m-commerce employees can be more responsive to customers, changes in the market and with all other organisational interactions which improve the overall productivity.

F.2: Increase revenues in existing segments and markets:

All of the respondents suggested that the mobility, convenience and accessibility that a customer has by using m-commerce, which brings products to the South African market to be purchased or to conduct m-commerce activities irrespective of the time or place will contribute to increasing revenue in existing markets. This perspective is also supported by [17] and [16]. Four of the respondents mentioned that the popularity of mobile devices in the South African market, being an emerging market where many do not have access to more conventional forms of commerce, is a key aspect for using m-commerce to increase revenues. [20] and [21] also suggested this, supporting William's comment that "there is a huge opportunity in SA as many potential customers are in the low to middle income bracket and may not have access to laptops etc. but have mobile devices".

F3: Grow revenues in new products and services:

Seven of the respondents said that $\mathrm{m}$-commerce provides an opportunity for many new products and services to be made available which in turn can potentially grow revenues. Brian added to this and said that "there are lots of opportunity for new m-commerce products and services with SA being an emerging market and many customers are low to middle income earners". Two of these seven respondents mentioned location-based services as an example of a m-commerce service that can be used to grow revenues. The seven respondents support [22] who suggests that organisations can gain a competitive advantage and grow revenues from new products and services, like location-based services, that $\mathrm{m}$-commerce can provide. Three respondents suggested that $\mathrm{m}$-commerce allows organisations to take products to the market faster by using m-commerce services like browsing catalogues and purchasing all from a mobile device which was also mentioned in the literature [13] and [16].

\section{Improve Operating Quality and Efficiency}

\section{C1: Be a leader in quality and reliability:}

Four respondents mentioned that m-commerce allows employees to work more efficiently and be more productive, which improves quality and assists an organisation to be a leader in quality and reliability. The literature review provided the same findings [13] and [15]. According to five respondents and literature, using $\mathrm{m}$-commerce can give you access to real time information which allows employees to make more informed decisions and stay up to date with changes in the environment while being mobile which also improves the quality and reliability [12].

There was no mention in the literature that was read regarding how using $\mathrm{m}$-commerce to receive up to date and instant customer feedback that could assist an organisation in being a leader in quality and reliability. However, all respondents said that the instant and relevant customer feedback an organisation can get from customers using $\mathrm{m}$ commerce can be used to instantly know what the customer wants or what issues there are and improve quality and reliability based on this feedback.

P1: Improve supply chain efficiency and effectiveness:

Eight of the respondents suggested that $\mathrm{m}$ commerce can improve the efficiency and effectiveness of the supply chain which is supported by the literature [16]. However, James said that the potential is there, but he thinks that this is still at an immature stage in the South African market due the complexity of supply chain management. Five of the respondents mentioned that m-commerce improves the communication between all parties involved in the supply chain which facilitates collaboration and that $\mathrm{m}$ commerce provides the advantage of having constant 
access to real time stock information which will improve the efficiency, effectiveness and overall coordination of the supply chain. The literature supported both of these advantages [13] and [16].

P2: Improve the quality, cost and flexibility of operating processes:

All nine respondents mentioned that m-commerce can make operating processes more flexible, efficient and reduce operating costs which supported the literature reviewed [12], [13] and [17] . However, James did say that you would have to look at the potentially reduced operating costs and weigh that up with the return on investment of $\mathrm{m}$-commerce applications. Literature as well as five of the respondents suggested that the advantage m-commerce provides of having access to real time information which allows employees to react faster to events in operating processes will improve the overall operating process [12] and [17].

\section{Grow High-Value Customer Relationships}

C2: Provide valued service, applications expertise, and support:

All of the respondents agreed with the literature and suggested that the ability of m-commerce to give organisations the opportunity to be in constant communication with a customer enables employees to better support customers and provide them with expertise [13], [15] and [22]. The literature showed that $\mathrm{m}$-commerce services need to bring value and be useful to customers in order to grow customer relationships [22]. Five respondents suggested that $\mathrm{m}$-commerce services that provide customers with relevant real time information can be used to bring value, better support customers and grow relationships. Location-based services were mentioned by three of the respondents as an m-commerce service that can also provide the customer with a valued service.

Furthermore, five of the respondents suggested that m-commerce can provide more personalised communication with the customer and four respondents mentioned that monitoring customer trends would assist in supporting the customer, both of which was not mentioned in the literature, but the respondents suggested that both will assist organisations to know how to support the customer better and provide a better service.

P3: Optimise customer profitability:

Six of the respondents suggested that the accessibility and convenience that $\mathrm{m}$-commerce can provide custo- mers by allowing them to conduct m-commerce transactions much more easily while on the go will optimise customer profitability which supported the literature [15], [17] and [22]. Seven of the respondents said that m-commerce can be used to optimise customer profitability by taking advantage of the opportunity it provides to market to customers in new ways. Three of these seven respondents mentioned that location-based services could be used which enable more strategic marketing. The literature supported both of these points [15] and [16].

The literature that was read did not mention efficiency as a factor to grow customer profitability, but Sean and James both suggested this with James saying that the efficiency that $\mathrm{m}$-commerce can provide organisations to conduct commerce can increase customer profitability by decreasing the costs.

\section{P4: Expand channels, offerings and markets:}

Seven respondents agreed with the literature in suggesting that the accessibility which $\mathrm{m}$-commerce provides as well as the opportunity m-commerce creates to market to customers using new channels can assist organisations in expanding channels, offerings and markets [13], [16] and [17]. Location-based services were mentioned by three respondents as an m-commerce service, which can add value and be used to expand channels, offerings and markets, which was supported by the literature [15], [16] and [23]. The literature was supported by four respondents who said that the convenience that $\mathrm{m}$-commerce gives customers to be able to purchase or conduct m-commerce transactions while being mobile can be used by organisations to expand channels, offerings and markets [13], [16] and [17]. James supported the literature in saying that there is a huge opportunity for South Africa, being an emerging market where many potential customers are in the middle to low income bracket, to expand channels, offerings and markets as many of these customers do not have easy access to personal computers or have the means to easily travel to brick and water stores but they do have mobile devices that can be used for m-commerce [20].

The literature that was read did not mention using m-commerce to monitor customer trends in order to expand channels, offerings and markets which was suggested by three of the respondents. P5: Build and maintain strong customer relationships All the respondents mentioned that m-commerce enables organisations to communicate much more efficiently with customers with four of these respondents mentioning that being able to provide customers with relevant up to date information builds and maintains strong 
relationships. These points were supported by the literature [15] and [16]. Five respondents agreed with the literature and suggested that $\mathrm{m}$-commerce assists organisations to provide customers with better and useful services and enables employees to be more efficient and respond to customers faster, all of which contributes to building and maintaining strong customer relationships [13], [14] and [22].

\section{E. Accelerate Product Innovation}

\section{C3: Introduce innovative, high-performance products and so-} lutions:

Four respondents agreed with the literature and said that an organisation can use the mobility characteristics of m-commerce to develop innovative, high performance products and solutions [13] and [14]. M-commerce services like location-based services were also mentioned as a means to develop innovative, high performance solutions which was supported by the literature [15] and [16]. Four of the respondents suggested that the customer feedback and new ideas organisations can get by using $\mathrm{m}$-commerce could assist organisations in developing innovative, high performance products and solutions by using customers to drive innovation and giving them what they want. The literature that was read did not mention what the four respondents suggested. The literature suggested, but was not mentioned by the respondents, that the productivity and efficiency benefits that $\mathrm{m}$-commerce gives employees can also contribute to providing innovative and high-performing solutions as employees have more time to plan, be inventive and focus on quality [13] and [16].

P6: Excel at technology, product development, and life cycle management:

All of the respondents suggested that organisations can use m-commerce to improve product development by allowing employees to work more efficiently and being constantly connected which was supported by the literature [13], [14] and [22]. The literature and four respondents mentioned that m-commerce facilitates better communication which assists organisations excel at life cycle management [13]. Three of the respondents agreed with the literature and suggested that m-commerce can create an opportunity and assist in excelling in technology [16]. Wayne mentioned the use of HTML5 in m-commerce applications and mobile sites, James mentioned technologies like Square can be used and Tim mentioned location-based services. Six respondents suggested that the ability for organisations to get up to date and relevant customer feedback can help customers excel at product development as improvements can be made faster and customers can get what they want. Two of these respondents also suggested that m-commerce can accelerate product development as m-commerce allows organisations to be constantly connected to the customer and the market. These points were not mentioned in the literature that was read.

\section{P7: Identify next generation market opportunities:}

All of the respondents suggested that m-commerce allows organisations to communicate with customers more efficiently, five of these respondents mentioned that communication via $\mathrm{m}$-commerce allows organisations to understand customers better and three respondents mentioned that this communication allows organisations to monitor customer trends more efficiently. These factors enable organisations to stay up to date with changing environments and markets, generate next generation marketing opportunities and create an opportunity to react and gain a competitive advantage, all of which was mentioned in the literature [12].

The literature suggested that next generation marketing opportunities can be identified through the use of u-commerce, which is a progression from m-commerce, but was not mentioned by any of the respondents [16].

\section{F. Create a High Performance Culture}

\section{L1: Expand and build strategic skills, capabilities and exper-} tise:

Four respondents agreed with the literature and suggested that organisations using $\mathrm{m}$-commerce allow employees to communicate with each other and share knowledge in an easy and convenient way which enables employees to learn from each other and build strategic skills, capabilities and expertise [13]. The mobility m-commerce provides allows employees the flexibility to do training and build skills and expertise at their own convenience irrespective of time and place, which was mentioned by four of the respondents and supported by the literature [13] and [16]. Four of the respondents suggested that employees can expand their capabilities and strategic skills by having constant access to real time information when using m-commerce, which was supported by the literature [13], [15] and [17].

Tim suggested that sharing organisational informational using $\mathrm{m}$-commerce can put the organisation at a security risk if not managed correctly, but this was not mentioned in the literature that was read. 


\section{L2: Develop a leadership and an execution-driven culture:}

Seven respondents agreed with the literature and suggested that because m-commerce can provide employees with real time information it creates a platform to develop a leadership and execution-driven culture [13]. Five of these respondents suggested that being mobile while having access to real time information enables employees to be more responsive and encourages an execution-driven culture, which was supported by the literature [13], [15] and [16].

Three of these respondents suggested that real time information enables employees to make better decisions and gives the confidence to execute them, which was supported by the literature [13], [15] and [16]. Two respondents agreed with the literature and mentioned that the services and tools that m-commerce can provide allow employees to execute tasks or procedures more easily and conveniently [15] and [16].

James said that while m-commerce will allow employees to be more responsive due to being mobile and having access to real time information, he feels that "leadership is found outside of technology and is more at a personal level", which was not mentioned in the literature that was read.

L3: Enable continuous learning and sharing of knowledge:

All of the respondents agreed with the literature and said that $\mathrm{m}$-commerce makes the sharing of knowledge within an organisation much easier and more convenient [13], [15] and [16]. Six of these respondents mentioned that as well as enabling the sharing of knowledge m-commerce also facilitates learning as employees can learn at their convenience from one another as well as from other sources, which was supported by the literature [13].

Four respondents mentioned that learning and the sharing of knowledge is made easier by the ability of employees to communicate better using m-commerce, which was supported by the literature [13] and [17]. Three respondents suggested that $\mathrm{m}$-commerce also allows organisations to learn more about the customer which in turn can be shared and communicated throughout the organisation, which was not mentioned in the literature that was read.

Tim again suggested that sharing organisation information using m-commerce can create a potential security risk if not managed correctly, which was not mentioned in the literature that was read.

\section{G. Summary of Findings}

The literature and the findings from the research responses indicated that South African retail organisations can use m-commerce to achieve all five of [9] strategic themes. The analysis did indicate that m-commerce is however more suited to achieve certain strategic themes than others.

The researcher looked at which objectives of each strategic theme were more strongly supported by the literature and the responses, indicating that these objectives were more suited to be achieved through m-commerce. According to the research the below objectives were more suited to be achieved using $\mathrm{m}$-commerce:

F.1: Improve productivity

F.2: Increase revenues in existing segments and markets

F3: Grow revenues in new products and services

P1: Improve supply chain efficiency and effectiveness

P2: Improve the quality, cost and flexibility of operating processes

C2: Provide valued service, applications expertise, and support

P3: Optimise customer profitability

P4: Expand channels, offerings and markets

P5: Build and maintain strong customer relationships

P6: Excel at technology, product development, and life cycle management

L3: Enable continuous learning and sharing of knowledge:

The findings indicated that m-commerce, within the South African retail context, is more suited to increasing return on capital, growing high value customer relationships, and improving operating quality and efficiency as all but one of the objectives for these strategic themes are listed above.

\section{CONCLUSION}

The main purpose of this research was to determine if South African retail organisations can use m-commerce to achieve their strategic objectives being increase return on capital, improve operating quality and efficiency, grow high value customer relationships, accelerate product innovation, and create a high performance culture.

The findings indicated that South African retail organisations can use m-commerce to achieve all their strategic objectives, but m-commerce within the South African retail context is more suited to increasing return on capital, growing high value customer relationships and improving operating quality and efficiency. 


\section{REFERENCES}

[1] A. Y. L. Chong, "Mobile commerce usage activities: The roles of demographic and motivation variables," Technological Forecasting and Social Change, vol. 80, no. 7, pp. 1350 -1359, 2013. DOI: 10.1016/j.techfore.2012.12.011

[2] A. Y. L. Chong, F. T. Chan and K. B. Ooi, "Predicting consumer decisions to adopt mobile commerce: Cross country empirical examination between China and Malaysia," Decision Support Systems, vol. 53, vol. 1, pp. 34-43, 2012.

[3] C. Lee, H. K. Cheng and H. Cheng, "An empirical study of mobile commerce in insurance industry: Task-technology fit and individual differences," Decision Support Systems, vol. 43, no. 1, pp. 95-110, 2007. DOI: 10.1016/j.dss.2005.05.008

[4] E. W. T. Ngai and A. Gunasekaran, "A review for mobile commerce research and applications," Decision Support Sys-

tems, vol. 43, no. 1, pp. 3-15, 2007. DOI: 10.1016/j.dss.2005.05.002

[5] H. Lin and Y. Wang, "An examination of the determinants of customer loyalty in mobile commerce contexts," Informa-

\& Management, vol. 43, no. 3, pp. 271-282, 2006. DOI: 10.1016/j.im.2005.08.001

[6] J. J. Castro-Schez, R. Miguel, D. Vallejo and L. M. Lopez-Lopez, "A highly adaptive recommender system based on fuzzy logic for B2C e-commerce portals," Expert Systems with Applications, vol. 38, no. 3, pp. 2441-2454, 2011. DOI: $10.1016 /$ j.eswa.2010.08.033

[7] M. S. Raisinghani, L. Meade and L. L. Schkade, "Strategic e-business decision analysis using the analytic network

pro- $\quad$ cess," IEEE Transactions on Engineering Management, vol. 54, no. 4, pp. 673-686, 2007.

DOI: $10.1109 /$ TEM.2007.906857

[8] L. Raymond and F. Bergeron, "Enabling the business strategy of SMEs through e-business capabilities: A strategic alignment perspective," Industrial Management \& Data Systems, vol. 108, no. 5, pp. 577-595, 2008.

DOI: $10.1108 / 02635570810876723$

[9] R. S. Kaplan and D. P. Norton, "Mastering the management system," Harvard Business Review, vol. 86, no. 1, pp. 62-77, 2008.

[10] M. Byrne, E. Keary and A. Lawton, "How to conduct a literature review," Irish Psychologist, vol. 38, no. 9-10, pp.

239- 245, 2012.

[11] D. Wagener, "Using cloud computing to achieve strategic objectives in South African enterprises," Master thesis, University of Cape Town, Cape Town, South Africa, 2012.

[12] M. M. Al-Debei, R. El-Haddadeh and D. Avison, "Defining the business model in the new world of digital business," in Proceedings of the Fourteenth Americas Conference on Information Systems, Toronto, Canada, 2008.

[13] H. Sheng, F. F. Nah and K. Siau, "Strategic implications of mobile technology: A case study using value-focused thinkJournal of Strategic Information Systems, vol. 14, no. 3, pp. 269-290, 2005. DOI: 10.1016/j.jsis.2005.07.004

[14] H. Kim, H. C. Chan and S. Gupta, "Value-based adoption of mobile internet: An empirical investigation," Decision Sup- $\quad$ port Systems, vol. 43, pp. 111-126, 2005. DOI: 10.1016/j.dss.2005.05.009

[15] P. Mahatanankoon, H. J. Wen and B. Lim, "Consumer-based m-commerce: Exploring consumer perception of mobile applications," Computer Standards and Interfaces, vol. 27, no. 4, pp. 347-357, 2005. D0I: 10.1016/j.csi.2004.10.003

[16] J. Wu and T. Hisa, "Developing e-business dynamic capabilities: An analysis of e-commerce innovation from I-, M-, to U-commerce," Journal of Organisational Computing and Electronic Commerce, vol. 18, no. 2, pp. 95-111, 2008.

[17] N. Mallat, M. Rossi, V. K. Tuunainen and A. Oorni, "The impact of use context on mobile services acceptance: The case of mobile ticketing," Information \& Management, vol. 46, no. 3, pp. 190-195, 2009. DOI: 10.1016/j.im.2008.11.008

[18] W. Gordon, "Behavioural economics and qualitative research-A marriage made in heaven?," International Journal of Market Research, vol. 53, no. 2, pp. 171-185, 2011. DOI: 10.2501/IJMR-53-2-171-186

[19] J. D. Aberbach and B. A. Rockman, "Conducting and coding elite interviews," Political Science \& Politics, vol. 35, no. 4, pp. 673-676, 2002. DOI: 10.1017/S1049096502001142

[20] J. Dörflinger, C. Friedland, C. Merz and R. de Louw, "Requirements of a mobile procurement framework for rural South Africa," in Proceedings of the 6th International Conference on Mobile Technology, Application \& Systems, Colorado, CO, 2009, pp. 3-7. DOI: $10.1145 / 1710035.1710038$

[21] M. Khalil and C. Kenny, "The next decade of ICT development: Access, applications and the forces of convergence," Information Technologies \& International Development, vol. 4, no. 3, pp. 1-6, 2008. DOI: 10.1162/itid.2008.00012 
[22] G. Buyukozkan, "Determining the mobile commerce user requirements using an analytic approach," Computer Stan- $\quad$ dards and Interfaces, vol. 31, no. 1, pp. 144-152, 2009. DOI: 10.1016/j.csi.2007.11.006

[23] N. Sultana and M. A. Islam, "Ubiquitous future M-Health system including wireless 3G technologies in Bangladesh," Journal of Advances in Technology and Engineering Research, vol. 1, no. 1, pp. 22-29, 2015. D0I: 10.20474/jater-1.1.3

[24] E. B. Nejad and R. A. Poorsabzevari, "A new method of winner determination for economic resource allocation in cloud computing systems," Journal of Advances in Technology and Engineering Research, vol. 2, no. 2, pp. 12-17, 2016. DOI: $10.20474 /$ jater-2.1.3

[25] W. H. Cho, C. Lim, S. Kim and S. Go, "Development of an innovative formwork system for casting reinforced concrete beams," International Journal of Technology and Engineering Studies, vol. 1, no. 1, pp. 14-18, 2015.

DOI: $10.20469 /$ ijtes.40003

— This article does not have any appendix. — 